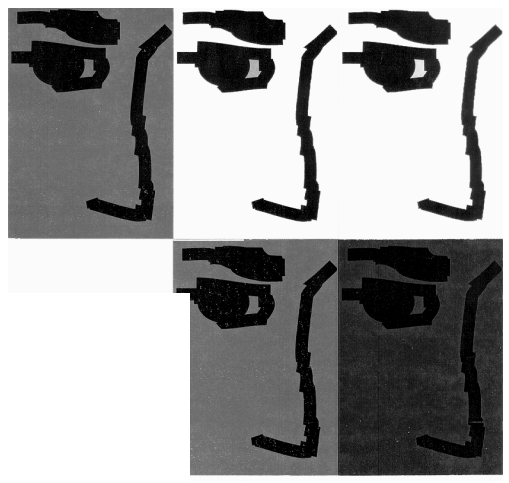

\title{
POLÍTICA DE INTERESSES, POLÍTICA DO DESVELO: REPRESENTAÇÃO E "SINGULARIDADE FEMININA"
}

\author{
LUÍS FELIPE MIGUEL
}

\begin{abstract}
Resumo: O artigo discute diferentes estratégias de justificação da adoção de quotas eleitorais por sexo, com ênfase naquelas que reivindicam um estatuto moral diferenciado para as mulheres. Elas introduziriam um novo tipo de política, mais desinteressado e altruísta, reflexo do seu treinamento social como responsáveis pelo cuidado com os mais fracos (a começar pelas crianças). No entanto, essa "política do desvelo" ou "política maternal" termina por perpetuar a inserção subordinada das mulheres no mundo da política, na medida em que o cartão de ingresso é exatamente a negação da ação em defesa dos próprios interesses.
\end{abstract}

Palavras-chave: política, mulheres, cotas, representaçâo, igualdade.

Em boa parte das democracias representativas — os países com regimes eleitorais de tipo ocidental — vigoram atualmente leis que visam incentivar a presença das mulheres nos centros decisórios, garantindo um número mínimo de candidaturas ou mesmo de assentos nos parlamentos e em instâncias dos poderes executivo e judiciário. Adotadas a partir do final dos anos 1970 nos países do norte da Europa, as "políticas de cotas" ganharam mundo e hoje estão presentes, inclusive, em muitos países latino-americanos. No Brasil, a reserva de vagas de candidatura para mulheres está em vigor desde as eleições municipais de 1996.'

A busca da ampliação da representação política das mulheres - ou de outros setores politicamente excluídos, como as "minorias" étnicas - está basea-

' Para um resumo da história da conquista das quotas no mundo e no Brasil, ver MIGUEL, 2000, p. 21-4. 


\section{POLÍTICA DE INTERESSES, POLÍTICA DO DESVELO}

da, em primeiro lugar, numa questão de justiça intuitiva. Como é possível que um grupo que inclui cerca de $50 \%$ da população adulta (na verdade, um pouco mais) ocupe apenas uns $5 \%$ das cadeiras no parlamento?

Trata-se de uma injustiça evidente; porém, é importante entender em que se funda esta "evidência". Existem outras desproporções que não são vistas como inadequadas. Pessoas de idade muito avançada (acima dos 80 ou 90 anos, por exemplo) tendem a estar sub-representadas nas diversas instâncias de governo, sem que isto cause consternação. Outro exemplo é o das crianças, que são excluídas de todos os direitos políticos - e o que causa espanto, via de regra, não é a exclusão, mas o fato de que alguns grupos tentem eliminá-la. Nos anos 1970, o educador John Holt propôs que os "direitos, privilégios, deveres e responsabilidades dos cidadãos adultos estejam disponíveis para qualquer jovem, de qualquer idade, que queira fazer uso deles", direitos que incluem voto, trabalho, privacidade, propriedade, possibilidade de fazer contratos e mesmo escolher parceiros sexuais. ${ }^{2}$ Não resta dúvida de que uma esmagadora maioria de pessoas consideraria absurda a proposta, revelando um amplo consenso em torno da idéia de que as crianças estão incapacitadas para o exercício destas funções.

No caso das crianças, a sua exclusão efetiva da arena política não é percebida como tal — ou seja, não é tematizada como um problema político porque se considera que é mera decorrência de uma característica natural, que as torna incapazes de promoverem os seus próprios interesses. Durante muito tempo, a participação política feminina foi encarada de forma semelhante. As revoluções burguesas dos séculos 17 e 18, inspiradas pelo ideário liberal, conciliaram, sem maiores hesitações, a afirmação de direitos humanos universais e a interdição do acesso das mulheres à esfera pública. Argumentos jurídicos e/ou naturais legitimavam o tratamento diferenciado, bloqueando a percepção da existência de uma injustiça.

\section{Justificando a exclusão das mulheres}

Os três principais autores contratualistas do período ilustram as diferentes estratégias para a justificação da exclusão feminina. ${ }^{3}$ Thomas Hobbes parte de um pressuposto pouco usual para a época, e à primeira vista contraditório com o resultado a que chega: a perfeita igualdade, quanto à capacidade física e mental, entre mulheres e homens. (Hobbes admite que existam disparidades naturais de talentos entre os indivíduos, mas nunca tão significativas que sustentem uma diferença de poder; por isso, fala na "perfeita igualdade" que vigoraria no estado

\footnotetext{
${ }^{2}$ Apud MEYROWITZ, 1985, p. 130 (ênfase suprimida).

${ }^{3}$ Uma abordagem extensa e instigante (embora nem sempre convincente) do tema foi feita por PATEMAN, 1993. Ela inclui tanto os contratualistas modernos quanto os contemporâneos (Rawls e outros), mostrando que, por trás do contrato igualitário voltado à proteção das liberdades individuais, jazem, ocultas, relações de subordinação e opressão, que ocorrem na esfera doméstica (e no trabalho). Não são relações contingentes, mas absolutamente necessárias para sustentar o edifício ideológico do contratualismo.
} 
LUÍS FELIPE MIGUEL

de natureza.) Ele apresenta uma narrativa em duas etapas. Primeiro, há a constituição de uma unidade familiar formada por mãe e filho (ou filha); de acordo com ele, trata-se de um pacto tácito, pelo qual a criança se obriga à obediência em troca de proteção. Ora, a maternidade fragiliza a mulher, que passa a ser responsável pela segurança de um outro ser, indefeso. Isto permite que o homem a domine, pela força. Para garantir a própria vida, mãe e filhos se submetem à autoridade do homem. ${ }^{4}$

Para Hobbes, mesmo sendo arrancado à força, este pacto é válido. Ele estende até a caricatura a ficção liberal de que um contrato é, por definição, voluntário, já que sempre existe outra alternativa (ainda que seja a morte). Assim, no momento em que os indivíduos se reúnem para celebrar o contrato social e gerar o Estado - a rigor, o único momento de existência de uma "esfera pública" no pensamento de Hobbes, já que o contrato promove a transferência de toda a autoridade para um soberano —- as mulheres não participam, pois já estavam previamente submetidas aos homens.

Na transição do contratualismo pró-absolutista, de Hobbes, para o liberal em sentido estrito, de John Locke, a posição das mulheres na verdade piora. Locke mantém o argumento jurídico, em versão reformulada, e acrescenta-lhe outro, natural. Através do contrato de casamento, as mulheres alienam os seus direitos, da mesma forma que os assalariados o fazem com o contrato de trabaIho. Mas esta alienação contratual já é o resultado de uma racionalidade inferior, que tornava ambos, mulheres e trabalhadores, inaptos para a participação na vida pública. ${ }^{5}$ Assim, o contrato apenas expressa o fato de que o homem é naturalmente "mais capaz e mais forte" do que a mulher, ${ }^{6}$ ao contrário do que pensava Hobbes. Como observa Pateman, o "'consentimento' aparente [das mulheres] à autoridade de seus maridos é apenas um reconhecimento formal de sua subordinação 'natural'". ?

Na medida em que rompe com o "individualismo possessivo" de seus predecessores, não reconhecendo validade em contratos que alienem direitos naturais, Jean-Jacques Rousseau inviabiliza o argumento jurídico para a exclusão das mulheres da esfera pública. A sua justificativa vai estar integralmente baseada nas diferenças intrínsecas aos dois sexos, que explora com certa detenção no trecho dedicado à educação de Sofia, no romance pedagógico Emílio. "Consultai o gosto das mulheres nas coisas físicas e que se prendem ao julgamento dos sentidos; o dos homens nas coisas morais e que dependem mais do entendimento", diz Rousseau, acrescentando: "Quando as mulheres forem o que devem ser, elas se limitarão às coisas de sua competência e julgarão sempre bem". ${ }^{8}$ Ou seja, a

\footnotetext{
${ }^{4}$ HOBBES, 1993, p. 130-7.

${ }^{5}$ Ver MACPHERSON, 1962; E PATEMAN, 1993.

${ }^{6}$ LOCKE, 1999, p. 454-5.

7 PATEMAN, 1989, p. 74.

${ }^{8}$ ROUSSEAU, 1992, p. 405.
} 


\section{POLÍTICA DE INTERESSES, POLÍTICA DO DESVELO}

limitação inata da razão e da capacidade de julgamento moral das mulheres torna necessário que elas permaneçam circunscritas ao círculo doméstico.

O projeto ético e político-pedagógico de Rousseau está centrado na recuperação das qualidades naturais do homem, que a sociedade corrompeu. No entanto, se ele não aceita que o homem moldado pelas sociedades existentes seja apresentado como representativo da "essência" natural do homem (e nisso antecipa a crítica que Marx fará aos pensadores utilitaristas), vê a mulher como sendo naturalmente aquilo que a sociedade de sua época fazia dela. Em parte devido à influência de sua obra, os revolucionários franceses de 1789 não tiveram problemas para excluir as mulheres da cidadania. Com exceção de Condorcet, de uns poucos nomes de menor expressão e de uma figura marginal como Olympe de Gouges, havia um consenso geral quanto à posição subordinada da mulher. Mais ainda, os principais líderes revolucionários nem sequer tocavam no assunto, indicando que a cidadania feminina estava mesmo fora de cogitação. ${ }^{9}$

Outras vozes isoladas se faziam ouvir no mesmo período, com destaque para a inglesa Mary Wollstonecraft (que, no entanto, esteve em Paris para acompanhar o desenrolar da Revolução Francesa). Mas só em meados do século seguinte o movimento sufragista ganhou força e visibilidade. Na maior parte dos países, as mulheres conquistaram o direito de voto por volta da primeira metade do século 20 - embora em alguns locais isto tenha ocorrido em data surpreendentemente tardia, como na Suíça, em 1971. A partir daí, é significativo o avanço na discussão do problema, num prazo historicamente curto.

\section{A busca da paridade}

A franquia eleitoral é logo acompanhada pelo direito de candidatura; umas poucas mulheres ocupam cadeiras no parlamento. Mas ao final do século 20, ao menos no mundo ocidental, a paridade dos sexos na representação política já era quase unanimemente vista como um objetivo justo. O Brasil serve de exemplo. No momento em que foi proposta a adoção de quotas de candidaturas (culminando na aprovação da lei no 9100/95), ouviram-se manifestações contra a medida específica, mas nenhuma voz significativa se elevou contra a meta de gerar uma representação política mais paritária. ${ }^{10}$ Embora continue presente nas práticas partidárias, a defesa da exclusão das mulheres já saiu do campo do discurso político legítimo.

O problema que se coloca é que os dois movimentos se apoiam em premissas diferentes. A defesa da extensão dos direitos políticos às mulheres se sustentava na afirmação da igualdade fundamental entre os sexos, ao menos quanto

\footnotetext{
${ }^{9}$ Ver a antologia de textos revolucionários e a apresentação de BADINTER, 1991.

${ }^{10}$ Assim, o Partido Popular Socialista (PPS), o único que encaminhou voto contrário às quotas de candidaturas em 1995, fez questão de afirmar a "alta importância" da participação das mulheres na política, embora privilegiasse, no caso, a autonomia partidária. Ver o discurso do deputado Sérgio Arouca, apud MIGUEL, 2000, p. 44.
} 
LUÍS FELIPE MIGUEL

à capacidade de participar do debate público e promover os próprios interesses. " Mas se a igualdade for considerada absoluta, a composição da representação política deve ser indiferente. Ou, pelo menos, se houvesse alguma diferença a ser considerada, a igualdade formal garantida pelas instituições liberais seria suficiente para expressá-la, sem a necessidade de mecanismos adicionais.

De fato, o princípio "um homem (depois acrescentado: ou uma mulher), um voto" deve permitir que cada indivíduo determine quais das suas características deseja exprimir na arena política: é o princípio liberal da auto-identificação do interesse que, combinado com um sistema eleitoral de representação proporcional, garantiria por definição uma justa constituição do parlamento. Neste caso, se as próprias mulheres julgassem importante a ampliação do número das suas representantes, elas a promoveriam, inscrevendo-se nos partidos, forçando o lançamento de candidaturas e elegendo mulheres. Se não o fazem, é porque não acham necessário. Seria legítimo procurar mudar esta avaliação, através do debate político, mas não forçá-la através de instrumentos legislativos como a adoção de cotas mínimas, o que limitaria a autonomia dos eleitores.

Portanto, a justificação de medidas especiais que favoreceram a representação feminina precisa encontrar uma argumentação que aponte diferenças entre homens e mulheres, que sustentem, por si sós, a necessidade da paridade. Inscreve-se, assim, no movimento mais amplo de valorização das diferenças, que eclode no discurso da esquerda a partir dos anos 1970 e 1980. Como demonstrou Pierucci, trata-se de um deslocamento repleto de "ciladas", uma vez que a afirmação da diferença - entendida como sinônimo de desigualdade ou, dito de outra forma, como diferença de mérito - é, desde há alguns séculos, a bandeira da direita. A tentativa de conciliação entre os valores divergentes da igualdade e da diferença exige contorcionismos teóricos e retóricos e, quando traduzida para a linguagem mais chã da prática política, dá margem a equívocos. ${ }^{12}$

De forma bastante esquemática, e sob a ressalva de que raras vezes os tipos se apresentam em estado puro, é possível apontar três linhas de raciocínio na defesa da paridade política: a afirmação de uma diferença moral entre homens e mulheres, de uma diferença de interesses ou de uma diferença estrutural. Para o presente artigo, interessa a primeira vertente, que afirma de forma mais radical (no sentido preciso da palavra) a especificidade da representação política das mulheres. As outras duas serão apresentadas apenas como contraponto.

Esta primeira corrente vai postular a singularidade do julgamento moral feminino. As diferenças que, de maneira preconceituosa, Rousseau apresentava (e, depois dele, muitos outros) não seriam o efeito do subdesenvolvimento da capacidade de julgamento das mulheres, mas de uma sensibilidade moral distinta da masculina. Dar espaço à representação política feminina seria dar voz, nas dis-

\footnotetext{
${ }^{11}$ É a ausência presumida desta capacidade que legitima a exclusão das crianças. 12 PIERUCCl, 1999.
} 


\section{POLÍTICA DE INTERESSES, POLÍTICA DO DESVELO}

cussões públicas, a esta outra sensibilidade, que hoje permanece circunscrita à esfera doméstica; por isto, é necessária a adoção de mecanismos que promovam a elevação da presença de mulheres nos foros decisórios.

A principal referência, na sustentação desta postura, é o livro da psicóloga estadunidense Carol Gilligan, In a Different Voice — um misto de pesquisa empírica e reflexão teórica, baseada, por sua vez, na revisão que a antropóloga Nancy Chodorow faz dos escritos de Freud sobre o impacto psicológico das diferenças anatômicas entre os sexos. Para Freud, a formação do superego está ligada à clara resolução do conflito edipiano, estimulada pelo medo da castração. O processo fica obviamente comprometido no caso das mulheres; por isto, conclui Freud, elas mostrariam "menos sentido de justiça do que os homens". ${ }^{13}$ Chodorow desloca a discussão; em vez da diferença anatômica, o que interessa é o fato de que as mulheres são as principais responsáveis pelo cuidado com os filhos. Assim, a menina possui um modelo (feminino) presente, a mãe, enquanto o menino possui um modelo (masculino) ausente, o pai. Isto faz com que as características masculinas do menino sejam desenvolvidas na forma de regras abstratas; já a menina desenvolve as suas características femininas a partir de relações concretas e emocionais. ${ }^{14}$

O modelo de Chodorow é bem mais complexo do que este resumo; o importante, para a presente discussão, é que ela apresenta o desenvolvimento de duas formas diferentes de relação com o mundo, em vez de apenas dois diferentes estágios da formação da moralidade, um avançado (o masculino) e o outro atrasado (o feminino). As mulheres possuiriam maior sensibilidade para as necessidades alheias, recusando a abordagem fria e impessoal que é própria da abordagem masculina da justiça.

Este é o ponto que Carol Gilligan desenvolve, através de uma série de entrevistas em profundidade com homens e mulheres, de diferentes idades. O resultado é a visualização de duas maneiras diferentes de pensar a moral. Um exemplo é a solução que duas crianças de 11 anos, Jake e Amy, dão ao "dilema de Heinz" — o sujeito que, diante da própria falta de dinheiro e da intransigência do farmacêutico, tem como opções roubar um remédio ou deixar a mulher morrer de uma doença grave. Jake traduz o dilema numa espécie de equação matemática, em que o direito de propriedade e o direito à vida se contrapõem. Dada a primazia do direito à vida, não é difícil concluir que Heinz deve roubar o remédio. A discussão se faz num nível abstrato e a solução a que se chega pouco tem a ver com a situação concreta; antes, toma a forma de uma norma geral, válida para todos os casos similares.

A solução de Jake, porém, não satisfaz Amy. Em vez de abordar o dilema como se fosse uma equação, a menina o vê como um momento numa relação

\footnotetext{
${ }^{13}$ Apud GILLIGAN, 1982, p. 7

${ }^{14}$ CHODOROW, 1978.
} 
LUÍS FELIPE MIGUEL

que se estende no tempo. ${ }^{15}$ Se Heinz roubasse o remédio, ele correria o risco de ser preso e, portanto, não poderia cuidar da mulher doente. Ela julga que é necessário buscar outras alternativas, que transcendem a formulação esquemática do problema, já que não se trata de decidir se a vida é mais importante do que a propriedade, mas de salvar o relacionamento ameaçado entre Heinz e a muIher. Talvez por isso suas respostas pareçam mais bisonhas: porque se recusam a permanecer nos limites estreitos apresentados pela questão. E não, como afirmava boa parte dos psicólogos voltados ao estudo do desenvolvimento moral, porque as mulheres não atingiam os patamares superiores do julgamento moral, caracterizados precisamente pela subordinação das relações interpessoais a regras associadas a padrões universais de justiça.

Gilligan recusa o essencialismo em sua abordagem, afirmando que o padrão moral alternativo, que descreve em seu livro, "é caracterizado não por gênero, mas por tema" e que "a sua associação com as mulheres é [apenas] uma observação empírica". ${ }^{16}$ A rigor, portanto, a sua preocupação seria alertar para a necessidade de reconhecer a legitimidade do padrão não-dominante de moral, e não especificamente apontar uma singularidade constitutiva das mulheres. Da mesma forma, Chodorow aponta que a reprodução da maternidade — que, na sua teoria, fornece a chave para a construção do papel feminino - ocorre "através de processos psicológicos socialmente induzidos", não sendo "nem um produto da biologia, nem de treinamento intencional". ${ }^{17}$

No entanto, a apropriação da obra de Gilligan e de Chodorow por teóricas políticas feministas como Sara Ruddick e Jean Bethke Elshtain, entre outras, resvalou com freqüência para uma postura essencialista. A diferença feminina pode não ser "natural", no sentido de "biológica", mas é vista como fundante da identidade das mulheres, de uma maneira tão elementar que, para todos os efeitos, está naturalizada. Um exemplo expressivo é a introdução do livro de Ruddick, em que ela narra como a experiência da maternidade lhe proporcionou a reconciliação com a sua identidade feminina - e o passo fundamental neste processo foi o distanciamento em relação à Razão masculina e opressora. ${ }^{18}$

\section{Uma política do cuidado}

Sob o nome de "política do desvelo" (care politics) ou então de "pensamento maternal", estas autoras afirmam que as mulheres trariam um aporte diferenciado à esfera políitica, por estarem acostumadas a cuidar dos outros e a velar pelos mais indefesos. Com uma presença feminina mais expressiva nas esferas de poder, haveria o abrandamento do caráter agressivo da atividade política, que é visto como sendo inerentemente masculino. As mulheres trariam para a

\footnotetext{
${ }^{15}$ GILLIGAN, 1982, p. 28.

16 GILLIGAN, 1982, p. 2.

${ }^{17}$ CHODOROW, 1978, p. 7

${ }^{18}$ RUDDICK, 1989, p. 3-12. Ver também ELSHTAIN, 1981.
} 


\section{POLÍTICA DE INTERESSES, POLÍTICA DO DESVELO}

política uma valorização da solidariedade e da compaixão, além da busca genuína pela paz; áreas hoje desprezadas nos embates políticos, como amparo social, saúde, educação ou meio ambiente, ganhariam atenção renovada.

A presença feminina possibilitaria a superação da "política de interesses", egoísta e masculina, colocando em seu lugar o desprendimento, o zelo pelos outros, a tolerância e a sensibilidade. ${ }^{19} \mathrm{O}$ central, nesta corrente, é a revalorização da esfera familiar, vista como o espaço de realização dos valores que são negados nas atividades públicas, sempre competitivas e egoístas. Com efeito, a moral feminina diferenciada, voltada para a manutenção dos relacionamentos interpessoais e ao cuidado concreto com os necessitados, manifestar-se-ia, em primeiro lugar, no papel de mãe de família. Responsáveis pela proteção e pelas condições para o crescimento sadio dos mais frágeis (as crianças), as mulheres veriam nesta tarefa um imperativo moral, que transportariam também para suas outras atividades. ${ }^{20}$

Graças a esta infusão de valores hoje considerados privados, a prática política se transformaria. Em vez da crua disputa pelo poder, haveria mais ética, generosidade e altruísmo. E em vez da frieza própria à justiça imparcial masculina, a atenção às necessidades de um "outro" que é percebido como ser concreto. É interessante observar que a segunda disjuntiva - norma abstrata versus responsabilidade concreta - ecoa, involuntariamente, as célebres distinções weberianas entre ética da convicção e ética da responsabilidade e entre o funcionário e o político. E as características vistas como femininas correspondem ao que, segundo as categorias do sociólogo alemão, é o âmbito próprio da política.

Weber julga que a atividade política não pode ser guiada por imperativos categóricos, já que o que importa não é a obediência estrita à norma ética, mas o resultado alcançado com tal atividade. De maneira semelhante, quem se prende à regra e a aplica friamente é o burocrata, não o político, que se distingue por assumir a responsabilidade pessoal pelos seus atos. Por esta leitura, os atributos masculinos estão na órbita da burocracia, e a feminização da política corresponderia à recuperação das suas características próprias. É claro que não é isto o que as teóricas do "pensamento maternal" querem dizer. O paralelo é contudo instrutivo, por revelar que, a par da repulsa pela disputa de poder, elas incorporam uma denúncia da gestão tecnocrática do Estado, esta sim fria e impessoal - e cuja ascensão corresponde, na verdade, a um recuo da esfera da política em sentido estrito.

A corrente leva a crer que a alteração dos padrões de comportamento na política será a decorrência natural da paridade da presença dos sexos nos foros decisórios. No entanto, a experiência de mulheres no poder revela que a relação

\footnotetext{
${ }^{19}$ DIAMOND E HARTSOCK, 1981.

${ }^{20}$ Para um resumo da discussão, com ênfase na sua crítica por outras correntes feministas, ver MOUFFE, 1992.
} 
LUÍS FELIPE MIGUEL

entre gênero e "política do desvelo" nada possui de automática. Os exemplos contrários são numerosos e tudo indica que, para o bem ou para o mal, mulheres e homens podem exercer o poder da mesma maneira. ${ }^{21}$

Por outro lado, no âmbito parlamentar, ao que parece, as mulheres se ocupam com mais freqüência de temas "sociais" do que de hard politics (administração pública, política econômica, relações internacionais). Mas isto ocorre, muitas vezes, porque se trata do único nicho disponível para elas no campo político. ${ }^{22}$ Assim, o sucesso das políticas que visam a ampliação da presença feminina nos foros de poder traria, como conseqüência, a destruição deste argumento, na medida em que permitiria que as mulheres disputassem, de forma mais intensa e com maiores possibilidades de êxito, também as áreas que hoje são quase-monopólio dos homens.

É legítimo argumentar que os temas considerados femininos são importantes, talvez até mesmo mais importantes do que os outros; concretamente, porém, trata-se das questões de menor prestígio do campo político, questões que exigem menos capital simbólico de quantos delas se ocuparão e lhes alavancam de forma menos expressiva a carreira futura. O discurso da "política maternal" propõe uma alteração da hierarquia de prestígio das atividades políticas, o que merece reflexão, mas ao mesmo tempo parece eternizar a divisão do trabalho político, insulando as mulheres no seu nicho próprio e destinando aos homens as tarefas que, ao menos por enquanto, são as mais valorizadas socialmente.

O componente essencialista presente nesta abordagem naturaliza a atribuição às mulheres das tarefas de cuidar dos outros, a sua abordagem da política e, finalmente, os papéis sexuais. Se é assim, não há sentido em cobrar dos homens a sua parcela de responsabilidade na educação das crianças ou, de forma mais geral, para com as gerações futuras. E a ausência de preocupação social na administração pública deixa de ser o efeito de um viés político que deve ser contestado para se tornar a conseqüência inescapável da diferenciação de gênero.

Outro questionamento significativo se refere à exaltação da atividade política desinteressada. Muito mais do que esterilizar as esferas decisórias da contaminação por uma "política de interesses", o problema que se coloca para as democracias representativas é permitir a expressão de interesses sociais hoje excluídos ou marginalizados. Isto inclui as próprias mulheres, de uma maneira que transcende a esfera política estrita.

\footnotetext{
${ }^{21}$ Basta lembrar da mais exitosa líder política do século 20, Margaret Thatcher, primeira-ministra do Reino Unido entre 1980 e 1991. O seu estilo político era integralmente condicionado pela disputa de poder; as reformas neoliberais que promoveu foram guiadas pelo desejo de se adequar às regras abstratas (para não dizer míticas) do mercado, com pouca atenção, e menos ainda desvelo, pelos indivíduos concretos que elas atingiriam. No Brasil, a mulher que alcançou o cargo de maior influência na história da República foi Zélia Cardoso de Mello, ministra da economia no início do governo de Fernando Collor (1990-1992); é difícil encontrar na sua gestão os traços de desvelo e compaixão que marcariam a política feminina.

22 Ver DELPHY, 1994.
} 


\section{POLÍTICA DE INTERESSES, POLÍTICA DO DESVELO}

A mulher é vista como agente de uma "política do desvelo" oposta à "política de interesses" porque é característica sua preocupar-se mais com aqueles que a cercam do que consigo própria. Está subjacente, neste argumento, a negação do direito da mulher a possuir interesses próprios ${ }^{23}$ — uma negação imposta pela sociedade patriarcal, emblematizada na figura da mãe que se sacrifica pelos filhos, e que esta corrente da teoria política feminista incorpora e exalta. Desta forma, a subalternidade é mantida e mascarada por um véu de "superioridade moral".

Além disso, é possível questionar se a maternidade é efetivamente um exemplo da conduta que se desejaria para a ação política. Trata-se de uma relação de desigualdade — o filho está subordinado à mãe, ao mesmo tempo em que as suas necessidades possuem primazia. No entanto, a política democrática exige igualdade, uma igualdade que inclui no cálculo o próprio sujeito, com suas carências e seus interesses, em vez de (como na exaltação convencional da maternidade) anulá-lo em prol do outro. O altruísmo de tipo republicano seria o de são Martinho, que, ao ver um mendigo passando frio, cortou seu manto em dois e ficou com uma metade, entregando a outra ao necessitado. Dar o manto inteiro ao mendigo seria fazer de si próprio um novo desabrigado. Negar as próprias necessidades não é instaurar uma sociedade mais igualitária, é apenas inverter a subalternidade.

Ademais, a maternidade é uma relação de intimidade e exclusividade (uma mãe não está preocupada com a maternidade em geral, mas com seus rebentos em particular), enquanto a cidadania requer as qualidades opostas de abertura e inclusividade. Tudo isto torna a relação entre mãe e filho, como observou Mary Dietz, "um modelo particularmente impróprio" para a vida pública. ${ }^{24}$

A virtude cívica da tradição republicana, reclamada por Dietz, aposta na capacidade de transcendência em relação ao círculo privado e na devoção voltada aos concidadãos. Por vezes, há algo de desumano neste valor, sobretudo nas formulações extremas, "exemplares", da Antiguidade. É o caso de Bruto, reverenciado pelos romanos como salvador da República, apresentado por Maquiavel como exemplo a ser seguido ${ }^{25}$. Entre os conspiradores que ele condenou à morte e a cuja execução assistiu estavam seus próprios filhos. ${ }^{26}$ É legítimo, e mesmo necessário, questionar que virtude é esta, que encarna o compromisso com uma abstração (o Estado) desvinculado de qualquer atenção aos próximos. Mas o remédio não parece ser o familismo proposto pelo "pensamento maternal", que, no limite, ao privilegiar os laços de união particulares, justifica o nepotismo, bane a referência ao bem comum e, enfim, dissolve a sociedade numa profusão de particularismos.

\footnotetext{
${ }^{23}$ PHILLIPS, 1991, p. 49

${ }^{24}$ DIETZ, p. 31.

${ }^{25}$ MAQUIAVEL, 1979, p. 313-22.

${ }^{26}$ Para uma narrativa do episódio, ver PLUTARCO, 1991, p. 209-12.
} 
LUÍS FELIPE MIGUEL

Um último argumento pode ser brandido contra a perspectiva da "política do desvelo", que tanto valoriza os atributos éticos e compassivos que seriam próprios da política feminina: ela está presa a uma leitura pré-maquiaveliana da política, vale dizer, a uma leitura que carece de realismo. ${ }^{27}$ Maquiavel não foi o defensor de uma política amoral, auto-interessada, voltada apenas para a conquista do poder, como muitas vezes se pensa. Ele identificou o drama fundamental da atividade políitca, que é a fragilidade intrínseca do bem quando confrontado ao mal. Ou seja, não adianta possuir boas intenções ou o firme desejo de agir bem, se isto vai levar, no fim, ao triunfo dos "maus". E os "maus" estão mais bem equipados para a vitória no confronto, já que se dispõem a usar todas as armas possíveis, enquanto os "bons" se recusam, por definição, a utilizar meios ilícitos. A única forma de barrar o triunfo da maldade parece ser o recurso às suas próprias armas.

Desta forma, as características tidas por "masculinas" da política - a sua amoralidade, a submissão dos meios aos fins, a crueza da disputa pelo poder se universalizam devido à sua eficiência superior. Os problemas da moral política são intrincados e não se esgotam nos escritos de Maquiavel. Mas permanece o fato de que ele nos colocou, já no século 16, diante de um dilema complexo. É possível querer uma política com novo conteúdo, em especial com mais ética, mas sem ignorar que este querer, por si só, não basta. Negar o realismo maquiaveliano, como fazem algumas teóricas do "pensamento maternal", ${ }^{28}$ significa recuar para uma postura ingênua, que em nada contribui para resolver a questão apresentada pelo pensador florentino.

\section{Identidade e interesse}

Todos estes problemas deixam claro que a afirmação da diferença moral entre homens e mulheres como base para a reivindicação da representação política paritária é dificilmente sustentável. Apesar de todas as ressalvas que as autoras mais sofisticadas tratam de fazer, enfatizando o caráter cultural dos comportamentos distintos de mulheres e homens, a abordagem acaba deslizando, sempre, para a naturalização da diferença. Como observa Pierucci, nos meios de esquerda "não se ousa dizer que elas [as diferenças] são naturais; diz-se que são diferenças culturais, só que irredutíveis. O que, se não dá no mesmo, dá quase". ${ }^{29}$

No entanto, é importante a discussão que esta abordagem ajuda a estabelecer sobre o conceito de justiça, que Agnes Heller chamou de "uma virtude fria, às vezes até mesmo cruel", ${ }^{30}$ e sobre o papel que a solidariedade pode desempenhar num ordenamento democrático. Embora voltada para um contexto diferente, as relações familiares, é este o ponto que Gilligan sublinha nas conclusões do

\footnotetext{
27 RAMSAY, 1995, p. 192-3.

${ }^{28}$ ELSHTAIN, 1995.

${ }^{29}$ PIERUCCl, 1999, p. 111

${ }^{30}$ HELLER, 1998, p. 27.
} 


\section{POLÍTICA DE INTERESSES, POLÍTICA DO DESVELO}

seu livro, observando que não se trata de substituir a ética "masculina" pela "feminina", mas de promover o diálogo entre a imparcialidade e a atenção. ${ }^{31}$

As outras vias de justificativa para a ampliação da representação feminina - que serão apenas indicadas aqui, como contraponto - partem de premissas opostas. As mulheres se devem fazer representar não porque sejam os vetores de uma "política desinteressada" mas, ao contrário, porque possuem interesses especiais, legítimos, ligados ao gênero, que precisam ser levados em conta. Quando o sistema político está estruturado de forma tal que veda ou obstaculiza a expressão destes interesses (ou de quaisquer outros), revela-se injusto.

Está subjacente, aí, a visão de que as mulheres serão as melhores advogadas dos seus próprios interesses. Somente quando esta crença se dissemina é que a sub-representação feminina passa a ser considerada iníqua - o que ajuda a entender por que, em geral, não se acha errado o déficit de representação de grupos como crianças ou doentes mentais, cujos interesses seriam melhor representados por outros (embora tal afirmação mereça ser relativizada).

Mas aí também permanece um "essencialismo" potencial subjacente. ${ }^{32}$ Parece que as mulheres, apenas por serem mulheres, terão sempre interesses idênticos. Contra isto, há o fato de que os indivíduos ocupam, ao mesmo tempo, diferentes "posições de sujeito", ${ }^{33}$ cujas pressões são variadas e, por vezes, contraditórias (por exemplo, mulher, negra, mãe, trabalhadora manual, evangélica, consumidora de determinado tipo de produtos, usuária de determinados serviços e moradora da periferia). Uma política de quotas que garanta a representação política feminina significa a imposição da primazia de uma faceta sobre as outras. Ou se retorna ao argumento liberal de que o mecanismo eleitoral permite que cada um escolha qual aspecto da sua identidade deve predominar, ou se promove uma segmentação total, sobrepondo as diversas clivagens, o que leva, no limite, à impossibilidade da representação política (se todas as minhas características pessoais devem estar espelhadas no representante, então somente eu me posso representar).

Além do mais - e este é um dos pontos fortes da argumentação por uma "política de idéias", atenta à plataforma dos representantes, e não às suas características individuais -, pertencer a um grupo não significa expressar as suas demandas. Mulheres candidatas não precisam ter comprometimento com a questão feminina, e muitas vezes não têm. Enfim, é questionável a própria noção de que existem interesses objetivamente identificáveis, ligados às posições sociais. As mulheres podem discordar, como de fato o fazem, sobre quais são os seus verdadeiros interesses ou quais as medidas políticas que devem apoiar.

${ }^{31}$ GILLIGAN, 1982, p. 173-4.

${ }^{32}$ ARAÚJO, 1998, p. 77.

${ }^{33}$ A expressão é de LACLAU, 1986. 
LUÍS FELIPE MIGUEL

Como diz a cientista política Eleni Varikas, a idéia ingênua da coincidência espontânea entre as ações das representantes e os interesses das suas eleitoras revela um entendimento deficiente da política, "pois pretende substituir o acordo acerca de idéias políticas pela confiança que teríamos nas representantes do nosso sexo". ${ }^{34}$ Ou seja, é uma postura que favorece a autonomização da elite política, que fica desobrigada de prestar contas ao eleitorado, uma vez que a sua legitimidade provém das características identitárias compartilhadas. No entanto, um dos desafios centrais das democracias contemporâneas é precisamente a ampliação do controle dos representantes, sejam mulheres ou homens, pelos seus constituintes de ambos os sexos.

A experiência do movimento operário serve de alerta quanto aos problemas que surgem com a postulação de que determinado grupo social possui interesses objetivos, que não precisam estar refletidos nas crenças subjetivas dos seus integrantes. Ela leva à dominação de um minoria dirigente, que se julga investida de uma capacidade superior de identificação de tais interesses e, assim, impõese de forma autoritária. Se é verdade que a crença liberal-utilitarista de que "cada um é o melhor juiz do seu próprio interesse" é cega aos constrangimentos estruturais que limitam o desenvolvimento da autoconsciência, pela sua parte a visão da objetividade do interesse de grupo elimina qualquer espaço de autonomia individual e, portanto, conduz ao desprezo pelos mecanismos democráticos.

A busca da superação destes problemas leva à terceira tendência de justificativa das políiticas de quotas. Iris Marion Young fala em "perspectiva social", ao invés de "interesse". ${ }^{35} \mathrm{O}$ acesso das mulheres (como de outros grupos politicamente excluídos) às esferas de deliberações públicas é necessário não porque compartilhem das mesmas opiniões ou interesses, mas porque partem de uma mesma perspectiva social, vinculada a certos padrões de experiência de vida. A palavra é relevante: trata-se de um ponto de partida, não de chegada.

É possível dizer, então, que a diferença significativa, do ponto de vista políti$\mathrm{co}$, entre mulheres e homens (e entre negros e brancos, trabalhadores e proprietários, etc.) não é uma diferença intrínseca, mas estrutural, ligada às posições que ocupam em dada formação social. Assim, a necessidade da presença das mulheres (como de outras minorias) na arena política não é suprimida caso se encontrem outras formas de proteger seus "interesses", qualquer que seja a forma pela qual eles sejam concebidos. Elas precisam estar presentes nos foros deliberativos e decisórios para que a perspectiva social que incorporam se faça ouvir e participe da construção de projetos coletivos - que, aliás, contempla a própria redefinição dos interesses dos envolvidos - que ocorre em tais foros.

\footnotetext{
${ }^{34}$ Ver VARIKAS, 1996, p. 79.

${ }^{35}$ YOUNG, 1997. A autora desenvolveu o tema em obra posterior; ver YOUNG, 2000.
} 


\section{POLÍTICA DE INTERESSES, POLÍTICA DO DESVELO}

O que está em jogo é a possibilidade de realmente se alcançar, na esfera política, o pluralismo de perspectivas que caracteriza sociedades fragmentadas como as contemporâneas. Medidas especiais, como a política de quotas, são necessárias porque a diferença estrutural se traduz na desigualdade da capacidade de intervenção na esfera pública. Vale lembrar a conclusão a que Pierre Bourdieu chega, ao estudar a auto-exclusão, na forma de apatia e desinteresse, daqueles que exercem menos influência política, nomeadamente as mulheres e as classes trabalhadoras: "a indiferença é apenas uma manifestação da impotência". ${ }^{36}$ Assim, a desigualdade estrutural, que aloca em proporções diferentes, segundo os grupos sociais, a capacidade de intervir no campo político é "naturalizada" pela adequação dos agentes ao comportamento que lhes é destinado. Mulheres, trabalhadores ou pessoas com pouca escolaridade estão sub-representadas porque "não se interessam" pela política, fato que as pesquisas de opinião pública demonstrariam com clareza...

A ação afirmativa é uma tentativa de romper este círculo vicioso, contribuindo para a redistribuição do capital político - ou, dito de outra forma, para o "empoderamento" (empowerment) dos segmentos sociais marginalizados. Em suma, ela se sustenta com a constatação da desigualdade presente na sociedade, sem necessitar de qualquer argumento essencialista ou da crença na "objetividade" de interesses comuns ao grupo. Neste sentido, as vozes das mulheres na política são, sim, "vozes diferentes". Não porque a diferença sexual produza uma singularidade moral, mas porque a organização da sociedade impõe experiências de gênero diferenciadas. A presença das vozes das mulheres - e de outros grupos excluídos politicamente - no debate público representa, então, um passo na direção da realização da democracia, entendida no seu sentido de "autonomia", isto é, a possibilidade de que os cidadãos e cidadãs fixem, eles próprios, as normas que regerão as suas vidas. É desta forma que se entende que, no final das contas, as políticas de quotas estão comprometidas com o valor ético da igualdade, ao buscarem, em suma, a participação igual na autonomia.

${ }^{36}$ BOURDIEU, 1979, p. 473. 
LUÍS FELIPE MIGUEL

\section{Referênclas blbllográflcas}

ARAÚJO, Clara. "Mulheres e representação política: a experiência das cotas no Brasil". Revista Estudos Feministas, v. 6, n. 1, 1998, p. 71-90.

BADINTER, Elisabeth. Palavras de homens. Rio de Janeiro: Nova Fronteira, 1991.

BOURDIEU, Pierre. La distinction: critique sociale du jugement. Paris: Minuit, 1979.

CHODOROW, Nancy. The Reproduction of Mothering. Berkeley: University of California Press, 1978.

DELPHY, Christine. "Feminismo e recomposição da esquerda". Revista Estudos Feministas, v. 2, no 1, 1994, p. 187-99.

DIAMOND, Irene, e HARTSOCK, Nancy. "Beyond Interest in Politics". American Political Science Review, v. 75, n. 3, 1981, p. 717-21.

DIETZ, Mary. "Citizenship with a Feminist Face: The Problem with Maternal Thinking". Political Theory, V. 13, n. 1, p. 19-37.

ELSHTAIN, Jean Bethke. Public Man, Private Woman. Princeton: Princeton University Press, 1981. "Reflection on War and Political Discourse: Realism, Just War, and Feminism in a Nuclear Age". Political Theory, v. 13, n. 1, 1995, p. 39-57.

GILLIGAN, Carol. In a Different Voice. Cambridge (Mass.): Harvard University Press, 1982.

HELLER, Agnes. Além da justiça. Rio de Janeiro: Civilização Brasileira, 1998.

HOBBES, Thomas. De cive, capítulo IX. Petrópolis: Vozes, 1993.

LACLAU, Ernesto. "Os novos movimentos sociais e a pluralidade do social". Revista Brasileira de Estudos Sociais, n. 2, 1986, p. 41-7.

LOCKE, John. Dois tratados sobre o governo. São Paulo: Martins Fontes, 1999.

MACPHERSON, C. B.. The Political Theory of Possessive Individualism. Oxford: Oxford University Press, 1962.

MAQUIAVEL. Comentários sobre a primeira década de Tito Lívio. Brasília: UnB, 1979.

MEYROWITZ, Joshua. No Sense of Place. Oxford: Oxford University Press, 1985.

MIGUEL, Sônia Malheiros. A política de cotas por sexo: um estudo das primeiras experiências no Legis/ativo brasileiro. Brasília: CFEMEA, 2000.

MOUFFE, Chantal. "Feminism, Citizenship and Radical Democratic Politics". In: BUTLER, Judith, e SCOIT, Joan W. (eds.). Feminists Theorize the Political. New York: Routledge, 1992.

PATEMAN, Carole. "Women and Consent". In: The Disorder of Women. Stanford: Stanford University Press, 1989.

. O contrato sexual. São Paulo: Paz e Terra, 1993.

PHILLIPS, Anne. Engendering Democracy. University Park: Pennsylvania State University Press, 1991. PIERUCCl, Antônio Flávio. Ciladas da diferença. São Paulo: 34, 1999.

PLUTARCO. Vidas paralelas, v. 1. São Paulo: Paumape, 1991.

RAMSAY, Maureen. "Machiavelli's Political Philosophy in The prince". In: COYLE, Martin (ed.). Niccolò Machiavelli's The Prince: New Interdisciplinary Essays. Manchester: Manchester University Press, 1995, p. 192-3.

ROUSSEAU, Jean-Jacques. Emílio ou Da educação. Rio de Janeiro: Bertrand-Brasil, 1992.

RUDDICK, Sara. Maternal Thinking: Towards a Politics of Peace. Boston: Beacon Press, 1989

VARIKAS, Eleni. "Refundar ou reacomodar a democracia? Reflexões críticas acerca da paridade entre os sexos". Revista Estudos Feministas, v. 4, n. 1, 1996, p. 65-94.

YOUNG, Iris Marion. "Difference as a Resource for Democratic Communication". In: BONHAM, James, e REHG, William (eds.). Deliberative Democracy. Cambridge: MIT Press, 1997. . Inclusion and Democracy. Oxford: Oxford University Press, 2000.

Politics of Interest, Politics of Care: Representation and "Women's Singularity".

Abstract: This article discusses different strategies for justifying the adoption of sex-based electoral quotas, emphasizing the type that claim a different moral status for women. The latter advocate introduction of a new type of politics, more unselfish and altruistic, which is supposed to reflect women's social training as those who are responsible for the care of those who are weaker (beginning with children). However, this "politics of care" or "maternal politics" ends up perpetuating the subordinate position of women in the world of politics, to the extent that the very grounds for their admission - their "entrance ticket", as it were-represents the negation of action in defense of women's own interests.

Keywords: politics, women, quotas, representation, equality. 